Cómo citar esta reseña: Reseña del libro Selva de fantasmas. El gótico en la literatura $y$ el cine latinoamericanos, de Gabriel Eljaiek Rodríguez. Estudios de Literatura Colombiana 43, pp. 207-212. DOI: https://doi. org/10.17533/udea.elc.n43a13

aavilleg@unal.edu.co

Universidad Nacional de Colombia, Sede Medellín

Recibido: 15.02 .2018

Aprobado: 06.06.2018
Copyright: $\odot 2018$ EstudiosdeLiteratura Colombiana. Este es un artículo de acceso abierto distribuido bajo los términos de la Licencia Creative Commons AtribuciónNo comercial -Compartir igual 4.0 Internacional

\section{SELVA DE FANTASMaS. El Gótico \\ EN LA LITERATURA Y EL CINE \\ LATINOAMERICANOS \\ Gabriel ElJaiek Rodríguez*}

\author{
Editorial Pontificia Universidad JaVeriana, \\ Bogotá, 2017, 222 P.
}

Andrés Villegas ${ }^{1}$

Muchos de los lectores recordarán las discusiones de la década de 1990 sobre el valor de los estudios culturales latinoamericanos y los riesgos que estos implicaban para disciplinas como los estudios literarios, la historia del arte o la antropología. En la actualidad, tal debate parece haberse moderado y es cada vez más frecuente la publicación en los países latinoamericanos de libros y artículos que podrían ser cobijados en esta categoría o, para ser más exactos, en la de Latin American cultural studies, dado que son productos de investigaciones desarrolladas en el mundo académico británico o estadounidense. El libro aquí reseñado es un ejemplo de esto.

Cada vez los investigadores se sienten más impulsados a plantear problemas que atraviesan las disciplinas por medio de la reunión de objetos de estudio provenientes de diversos campos de las artes. También se vuelven más comunes las investigaciones que sobrepasen las fronteras nacionales y los periodos específicos. Este es el caso de Selva de fantasmas, libro que se ocupa del cine y la literatura de tres países o zonas: el Río de la Plata, Colombia y México, en tres periodos que cubren casi un siglo: desde la primera década del siglo xx hasta 1993. Lo anterior implica cierto desinterés en cuestiones de carácter formal, pero también permite un acercamiento interesante en tanto que, sin desdeñar estrategias metodológicas y perspectivas teóricas propias de los estudios literarios y del cine, se ocupa explícitamente de la relación entre producciones culturales y sociedad. 
El nudo que permite atar cuentos, novelas y películas a problemas como el género, la etnia y la clase es la noción de tropicalización de lo gótico:

[...] mecanismo por el cual se recicla y transforma el género gótico en América Latina, poniendo fuera de lugar a personajes y temas para realzar la artificialidad del género y sus dinámicas de construcción y enunciación de lo otro y para posibilitar la enunciación de aquello de lo cual "no se puede hablar" - que dependiendo del contexto puede ser la violencia, desigualdades sociales o tabúes culturales como el incesto o lo abjecto [sic] — (Eljaiek Rodríguez, 2017, p. 10).

La construcción de este mecanismo como la noción articuladora del texto está inscrita en la propia tradición de los estudios culturales latinoamericanos, los cuales se han caracterizado por el interés en las diversas formas de apropiación artística realizadas en nuestro subcontinente; apropiación que fue teorizada por ensayistas e investigadores a través de conceptos como antropofagia (vanguardia brasilera), calibanismo (Roberto Fernández Retamar), transculturación (Fernando Ortiz y Ángel Rama), heterogeneidad cultural (Antonio Cornejo Polar) o hibridación (Néstor García Canclini). Si el gótico europeo debe ser comprendido, a juicio de Eljaiek Rodríguez, como una escritura de la otredad, en la cual se busca generar en los lectores sensaciones de miedo, angustia, repulsión y terror, a través de la conversión del otro en algo monstruoso o, cuando menos, sobrenatural, la tropicalización de lo gótico implica entonces un proceso de transculturación narrativa que rearticula y pone fuera de lugar elementos de una tradición narrativa espacial y temporalmente lejana; y al hacer esto desfamiliariza o torna extraños los elementos propios y ajenos, a través de una ligera variación que los convierte en ejemplos fehacientes de lo ominoso freudiano. Se trataría, en suma, aunque el autor no lo haga explícito, de una otredad de segundo grado.

El primer capítulo, "Tren al sur: tropicalización del gótico en el Río de la Plata", se concentra en varios cuentos y una novela corta del escritor uruguayo Horacio Quiroga, aunque también se ocupa, con menor detalle, de relatos de Leopoldo Lugones, para finalizar haciendo mención a obras de Adolfo Bioy Casares, Silvina Ocampo, Julio Cortázar y Alberto Laiseca, lo cual le permite a Eljaiek Rodríguez mostrar la constante preocupación de los escritores rioplatenses por la apropiación de las convenciones góticas. La escogencia de Quiroga como eje central se debe, seguramente, a que será él quien las tropicalice de una forma más decidida y recurrente en sus textos, lo cual puede parecer extraño en tanto el espacio en el que ocurren las historias 
no es, precisamente, el trópico; no obstante, es asociado a lo tropical por cuanto está ubicado en Latinoamérica y muchos de los relatos ocurren en zonas húmedas, calientes y consideradas salvajes.

Las narraciones de Quiroga que son tomadas como objeto de estudio se pueden dividir en dos tipos: aquellos en los cuales la presencia de animales va a ser central, como en "El almohadón de plumas" (1917) y "El mono que asesinó" (1909); y los cuentos vinculados al cine. En los primeros, que son analizados junto a "Yzur" (1906) de Lugones, se resalta el fracaso de la razón humana en su encuentro con seres que se suponen a priori como irracionales, pero que en el caso de los monos instauran lo ominoso al ser casi humanos o incluso más humanos que los propios homo sapiens. En el segundo caso, se toman cuentos como "Miss Dorothy Phillips, mi esposa" (1919), "El espectro" (1926), "El vampiro" (1927) y "El puritano" (1921), en los cuales el cine, y en general la técnica moderna, se relaciona con la capacidad de proyectar lo inmaterial e inmortalizar a los seres humanos. Para Quiroga, la ciencia y la técnica están encantadas e incluso malditas, retomando así una relación que si bien hoy nos puede parecer extraña, fue muy común desde finales del siglo XIX: el reencantamiento de la técnica que la mezclaba sin pudor con fenómenos como el espiritismo o la reencarnación, tal como lo señaló, para el caso rioplatense, Beatriz Sarlo en su clásico $L a$ imaginación técnica: sueños modernos de la cultura argentina, en el cual se ocupa ampliamente de Quiroga. En este sentido, extraña un poco que el autor no explore más la línea abierta por Sarlo o le dé más alcance a la dimensión espectral del cine a través de los planteamientos de Derrida, los cuales ha citado.

"Unos pocos buenos amigos del gótico tropical en Colombia" es el título del segundo capítulo y hace referencia a la expresión utilizada por el cineasta Carlos Mayolo para referirse a sus dos largometrajes: Carne de tu carne (1983) y La mansión de Araucaima (1986); a estas películas se suma Pura sangre (1982) de Luis Ospina. Ambos cineastas trabajarían juntos en numerosas ocasiones y harían parte del "Grupo de Cali". Este capítulo es particularmente relevante por dos razones fundamentales. La primera, es que la atención recae sobre la producción cultural colombiana. La segunda, remite a que las obras analizadas allí permiten reflexionar explícitamente sobre la posibilidad del gótico en el trópico.

Las tres películas, a pesar de sus diferencias, tienen en común el realizar una apropiación bastante consciente y cinéfila de los referentes del 
gótico tanto literario como cinematográfico, para ambientarlo en un territorio tropical, ya sea urbano o rural, poniendo así los referentes tradicionales en 'fuera de lugar'. Los vampiros se desdoblan en magnates ancianos y moribundos que necesitan sangre de jóvenes y niños varones para vivir, y en sus empleados que consiguen a estas víctimas que desangran, violan y asesinan en Pura sangre; o en las espectrales figuras de Margaret y Andrés Alfonso, los dos hermanos medios incestuosos de Carne de tu carne, que luego de ser asesinados regresan como una mezcla de vampiros, zombies y personajes de la tradición oral colombiana como la madremonte y el mohán. Como lo muestra Eljaiek Rodríguez, y ha sido también resaltado por Marc Berdet, Felipe Gómez Gutiérrez, María Inés Martínez, Juana Suárez y David Wood, Carne de tu carne y Pura sangre combinan el horror sobrenatural con el horror social producido por las violencias colombianas y hacen del vampirismo una alegoría que expresa el desangramiento de larga duración al que han sido sometidas las clases trabajadoras vallecaucanas por parte de los empresarios de esta región, que han buscado constituirse en algo más que una clase: una casta separada genéticamente de sus subordinados. $L a$ mansión de Araucaima, por su parte, está basada en la novela de Álvaro Mutis y tropicaliza el gótico al reubicar la casa o el castillo encantado en un ambiente exuberante y caliente, en el cual una serie de personajes están enclaustrados en un precario equilibrio que se rompe por la llegada de una joven.

La novela de Mutis, publicada en 1973, será fundamental desde su mismo subtítulo: Relato gótico de tierra caliente. Carlos Mayolo, en sus memorias tituladas Mamá, ¿qué hago?, relata que acuñó la denominación gótico tropical a partir de la polémica que sostuvieron, cuando ambos estaban asentados en México, el director español Luis Buñuel y el escritor colombiano Álvaro Mutis, sobre la posibilidad de trasladar el gótico inglés a las tierras tropicales. La respuesta de Mutis fue La mansión de Araucaima, en la cual se apropió el tropo de la casa o castillo embrujado, iniciado por Horace Walpole en El castillo de Otranto (1764) y popularizado en la literatura por autores como Edgar Allan Poe y H. P. Lovecraft. Este tropo, si bien el autor de Selva de fantasmas no lo hace, podría incluso ser conceptualizado como un cronotopo en tanto remite a una amalgama inseparable de espaciotiempo, un espacio marcado por su cierre sobre sí mismo: la casa embrujada se presenta como un espacio básicamente autosuficiente y clausurado, no en vano tanto en la novela como en la película las leyes de la casa están 
resumidas en la siguiente frase: "Si entras en esta casa no salgas. Si sales de esta casa no vuelvas. Si pasas por esta casa no pienses. Si moras en esta casa no plantes plegarias". A la par, la dimensión temporal está marcada por el estatismo, en una especie de tiempo por fuera del tiempo, en el cual todo permanece igual y el cambio solo puede significar el derrumbe completo de la forma de vida que los habitantes de la mansión han construido.

El tercer capítulo, "Allá en el rancho grande: Drácula y la tropicalización del gótico en México", combina acercamientos a la literatura y al cine. En un primer momento se ocupa de la novela corta "Vlad" de Carlos Fuentes, publicada en Inquieta compañía; allí el escritor mexicano literalmente pone fuera de lugar al vampiro por excelencia del gótico al trasladarlo a Ciudad de México. De este relato pasa a dos películas propias del "cine de luchadores": Santo vs. Las mujeres vampiro (1962) y Santo y Blue Demon contra Drácula y el Hombre Lobo (1973), cuyos títulos dan claras muestras de la labor de apropiación y mezcla de referentes, de convenciones temáticas y narrativas. Finalmente, el capítulo retoma una película más reciente y con mayores pretensiones artísticas como La invención de cronos (1993) de Guillermo del Toro, en la cual se hace un giro importante al convertir al vampiro en un dispositivo alquímico-mecánico habitado por un insecto que vive de la sangre de su anfitrión. El relato y las tres películas, a pesar de sus marcadas diferencias, combinan la figura clásica del vampiro con el imaginario mexicano y con la vida en una urbe densamente poblada, en la cual un ser que vive de la sangre de los demás puede pasar fácilmente desapercibido.

Después de este recorrido es claro para los lectores - y esto es, por supuesto, un mérito del libro- que la tropicalización del gótico está sustentada en un uso bastante consciente de las fuentes, las cuales son subvertidas. Hay, pues, homenaje y burla. Al mismo tiempo, esta tropicalización permite representar de forma alegórica los profundos conflictos que atraviesa América Latina, conflictos que han estado marcados por la conversión de los otros en encarnaciones de una alteridad radical temida por las élites. Si bien este punto es planteado explícitamente por el autor, tal vez requeriría un desarrollo más profundo. Para los lectores interesados en la literatura colombiana, seguramente hubiera sido interesante que el autor analizara la novela de Mutis y la forma en que fue adaptada por Carlos Mayolo. No obstante, se trata de una investigación que realiza un aporte importante a una de las líneas centrales de los estudios culturales y literarios latinoamericanos: aquella centrada en la transculturación narrativa, la cual 
ha sido más ampliamente desarrollada en los acercamientos a la literatura caribeña o a la literatura indigenista peruana, ecuatoriana y boliviana, pero que recientemente ha recibido un nuevo impulso con esta obra y con el libro del investigador brasilero Idelber Avelar Transculturación en suspenso: los orígenes narrativos de los cánones narrativos colombianos (2015). 